\title{
EFEITO DA IRRIGAÇÃO NO RENDIMENTO E QUALIDADE DE FIBRAS EM CULTIVARES DE ALGODOEIRO HERBÁCEO ${ }^{1}$
}

\author{
JOÃO HENRIQUE ZONTA ${ }^{2 *}$, JOSÉ RENATO CORTEZ BEZERRA², VALDINEI SOFIATTI², FRANCISCO JOSÉ \\ CORREIA FARIAS ${ }^{2}$, LUIZ PAULO DE CARVALHO ${ }^{2}$
}

\begin{abstract}
RESUMO - Objetivou-se avaliar a produtividade, o rendimento e a qualidade de fibras de cultivares de algodoeiro herbáceo submetidas a diferentes lâminas de irrigação. Durante dois anos consecutivos foi conduzido um experimento de campo na região de Apodi (RN) disposto em parcelas subdivididas com quatro lâminas de irrigação (130, 100, 70 e 40\% da evapotranspiração da cultura - ETc) e quatro cultivares de algodoeiro (FiberMax 993, BRS 286, BRS 336 e BRS 335), em delineamento de blocos casualizados com quatro repetições. Foram avaliadas a produtividade, a percentagem e a qualidade das fibras do algodoeiro. Houve diferença significativa para as características avaliadas entre as cultivares e as lâminas de irrigação. A rega com déficit (70 e 40\% ETc) ocasionou declínio na produtividade de algodão em caroço, na percentagem e qualidade das fibras. As cultivares FiberMax 993 e BRS 286 apresentaram as maiores produtividades e percentagem de fibras entre as cultivares avaliadas. Com a lâmina de $40 \%$ da ETc as cultivares de fibra média (FiberMax 993, BRS 286 e BRS 335) apresentaram fibras curtas, e a cultivar de fibra longa (BRS 336) apresentou fibra média. De forma geral, a redução na qualidade da fibra não foi severa, haja vista a fibra produzida está dentro da faixa de qualidade aceitável pela indústria têxtil nacional, mesmo em condições de déficit hídrico. Dessa forma, a decisão em irrigar o algodoeiro com ou sem déficit hídrico dependerá dos custos da irrigação e do valor de mercado do produto.
\end{abstract}

Palavras-chave: Déficit hídrico. Algodão. Semiárido.

\section{EFFECT OF IRRIGATION ON YIELD AND FIBER QUALITY IN COTTON CULTIVARS}

\begin{abstract}
This study was conducted to evaluate seed cotton yield, fiber yield, and fiber quality traits of cotton cultivars grown under different irrigation levels in Brazil. The experiment was conducted over two years in the region of Apodi - RN, with sprinkler irrigation. Treatments comprised of 4 irrigation levels i.e., 130, 100, 70 and $40 \%$ of the crop evapotranspiration (ETc) and 4 cotton cultivars i.e., FiberMax 993, BRS 286, BRS 336 and BRS 335. The experimental design was factorial with randomized complete block design and four replicates. Yield, lint percent and fiber quality traits determined were evaluated. Different responses were observed for cultivars at various irrigation levels. Cultivars grown under limited irrigation exhibited a decline in the seed cotton yield, lint percent, and fiber quality. Cultivars with the highest yield and lint percent were FiberMax 993 and BRS 286. Within irrigation level of $40 \%$ ETc, the medium fiber cultivars produced short fibers whereas the long fiber cultivar, BRS 336, produced medium fiber length. Overall, the different levels of water deficits did not significantly affect fiber quality of the four cultivars tested as all fiber quality traits remained acceptable for the domestic textile industry.
\end{abstract}

Keywords: Water deficit. Cotton. Semiarid.

\footnotetext{
*Autor para correspondência

${ }^{1}$ Recebido para publicação em 05/05/2014; aceito em 18/05/2015.

${ }^{2}$ Embrapa Algodão, Caixa Postal 174, 58428-095, Campina Grande (PB); joao-henrique.zonta@embrapa.br.
} 


\section{INTRODUÇÃO}

Nos últimos anos a demanda hídrica nos centros urbanos tem crescido rapidamente decorrente do crescimento populacional e a melhoria de renda da população, criando uma série de problemas, principalmente em regiões onde os recursos hídricos são escassos, como o semiárido do nordeste do Brasil. Essa situação cria a necessidade de se desenvolver pesquisas que visem o uso sustentável daqueles recursos, tanto nas zonas urbanas quanto na agricultura, a qual, com uso da irrigação, é responsável por 54\% da água consumida no Brasil (ANA, 2013).

Dessa forma, o decréscimo na disponibilidade hídrica pode acarretar uma necessidade de alterações e adaptações nas estratégias de irrigação, visto que em muitas regiões a rega poderá ser limitada pela baixa disponibilidade hídrica (SNOWDEN et al., 2013).

O cultivo de algodão irrigado na região semiárida é uma ótima oportunidade para o setor algodoeiro, visto que devido às características climáticas na região semiárida são produzidas fibras de ótima qualidade, e em áreas irrigadas são alcançadas excelentes produtividades (BRITO et al., 2011). Nesse ínterim, deve-se buscar nas pesquisas melhorias no manejo da irrigação do algodoeiro visando obtenção de elevadas produtividades, alta qualidade de fibra e maior eficiência de uso de água pela cultura.

Uma das práticas que vem sendo difundida para reduzir o gasto de água na irrigação é o uso da rega com déficit hídrico controlado, a qual mantém a produtividade das culturas elevando a eficiência de uso da água, de modo a garantir o retorno da produção por unidade de água aplicada, aumentando a sustentabilidade do sistema.

Segundo Basal et al. (2009), Dagdelen et al. (2009) e DeTar (2008) o decréscimo na disponibilidade hídrica tem conduzido a pesquisas sobre o requerimento de água de diversos cultivos, bem como ao estudo do impacto da irrigação com déficit no rendimento e na qualidade dos produtos.

Para o algodoeiro, diversos autores como Wen et al. (2013), Brito et al. (2011), DeTar (2008) e Pettigrew (2004) tem demonstrado que a cultura sofre influência tanto na produtividade quanto na porcentagem e qualidade de fibras quando submetido à irrigação com déficit hídrico. Santana et al. (2008) afirmam que apesar de serem condicionadas por fatores hereditários as características tecnológicas da fibra do algodão sofrem decisiva influência dos fatores ambientais (temperatura, luminosidade, disponibilidade hídrica) e dependem das condições de cultivo.

O estudo de diferentes cultivares de algodoeiro irrigado com diferentes lâminas de irrigação na região semiárida é importante, visto ser possível encontrar cultivares que apresentem respostas diferen- tes quando submetidas ao déficit hídrico, o que acarretará em maior eficiência de uso da água e do sistema produtivo. Além disso, é pertinente testar até que ponto as novas cultivares respondem à irrigação, visto que muitas delas foram desenvolvidas para condições do Cerrado e seus coeficientes de cultivo podem estar subestimados para as condições do Semiárido.

À luz das considerações ora pontuadas, o objetivo deste trabalho foi avaliar a produtividade e a qualidade de fibras em cultivares de algodoeiro de fibras média e longa, cultivadas na região semiárida, submetidas a diferentes lâminas de irrigação.

\section{MATERIAL E MÉTODOS}

O experimento foi conduzido durante os anos de 2012 e 2013 na Fazenda Experimental da Empresa de Pesquisa Agropecuária do Rio Grande do Norte (EMPARN), localizada no município de Apodi $(\mathrm{RN})$, cujas coordenadas geográficas são 5³7'19" S de latitude e $37^{\circ} 49^{\prime} 06^{\prime \prime} \mathrm{W}$ de longitude, com altitude variando entre $128 \mathrm{~m}$ e $132 \mathrm{~m}$. O clima da região é caracterizado como tropical quente e semiárido, com predominância do tipo BSw'h', segundo classificação climática de Köppen, e estação chuvosa iniciando no outono. O solo da área experimental foi classificado como Cambissolo eutrófico, de textura argiloarenosa, com $49 \%$ de areia, $45 \%$ de argila e $6 \%$ de silte.

Adotou-se o delineamento experimental em blocos ao acaso, em esquema fatorial $4 \times 4$, com parcelas subdivididas e quatro repetições, sendo o experimento conduzido em dois ciclos de cultivo. Os tratamentos foram constituídos por quatro lâminas de irrigação alocadas nas parcelas (40, 70, 100 e 130\% da evapotranspiração da cultura - ETc) e quatro cultivares de algodão herbáceo (BRS286, BRS335, BRS336 e FiberMax 993) alocadas nas subparcelas. Cada unidade experimental foi constituída por seis fileiras espaçadas de 0,84 metros, com 7,5 metros de comprimento, totalizando uma área de $37,8 \mathrm{~m}^{2}$, sendo considerado como área útil as 4 fileiras centrais, excluídos $1,25 \mathrm{~m}$ de cada extremidade.

Do plantio até o início dos tratamentos (Tabela 1) as irrigações foram realizadas de forma igual em todas as parcelas, de modo a garantir o pleno estabelecimento das plantas, sendo a lâmina de irrigação determinada em função da evapotranspiração da cultura, com turno de rega de 3 dias. As irrigações se encerraram quando a cultura apresentou $60 \%$ de capulhos abertos.

O cultivo foi realizado no sistema plantio direto (SPD), sendo o plantio realizado com plantadeira mecanizada de 4 linhas, não sendo necessário a realização de desbaste.

Os dados agronômicos e da irrigação são apresentados na Tabela 1. 
Tabela 1. Dados agronômicos e parâmetros da irrigação durante o ciclo de cultivo do algodoeiro, Apodi (RN), 2012 e 2013.

\begin{tabular}{lcc}
\hline Variáveis & 2012 & 2013 \\
\hline Data de plantio & $30 / 07 / 2012$ & $19 / 08 / 2013$ \\
Densidade de plantio & $8-12$ plantas m $^{-1}$ \\
Adubação de plantio & $280 \mathrm{Kg} \mathrm{de} \mathrm{MAP}^{*}$ ha $^{-1}$ \\
Adubação de cobertura & $350 \mathrm{Kg} \mathrm{de} \mathrm{Uréia} \mathrm{ha}^{-1}$ \\
Início dos tratamentos de irrigação & $08 / 09 / 2013(15 \mathrm{DAG})$ \\
Última irrigação $^{\text {Data da colheita* }}$ & $07 / 11 / 2012(97 \mathrm{DAG})$ & $24 / 11 / 2013(92 \mathrm{DAG})$ \\
$\begin{array}{l}\text { Duração do ciclo de cultivo } \\
\text { Precipitação total durante o ciclo de } \\
\text { cultivo }\end{array}$ & $04 / 12 / 2012$ & $11 / 12 / 2013$ \\
\end{tabular}

* MAP - Monoamônio fosfato; DAG - Dias após a germinação; a colheita das quatro cultivares foi realizada na mesma época.

As irrigações foram realizadas com um sistema de aspersão convencional fixo, com espaçamento entre aspersores de $12 \times 15 \mathrm{~m}$, intensidade de aplicação de $10 \mathrm{~mm} \mathrm{~h}^{-1}$ e coeficiente de uniformidade de Christiansen (CUC) igual a 85\%, sendo as irrigações realizadas a cada 4 dias. Para evitar que houvesse aplicação de água nas parcelas vizinhas, ou seja, entre os tratamentos, foi deixado um espaçamento de 15 metros entre cada, de modo que as parcelas de cada tratamento fossem isoladas dos demais.

Para o cálculo da lâmina de reposição utilizou -se a seguinte expressão:

$$
\mathrm{L}_{\text {irrig }}=\mathrm{ETc} / \mathrm{f}
$$

em que Lirrig é a lâmina bruta de irrigação, mm; ETc é a evapotranspiração da cultura acumulada (4 dias), mm; e f é a eficiência de aplicação (considerada igual a 0,85 , valor do CUC), decimal.

A evapotranspiração da cultura (ETc) foi dada pela equação 2 :

$$
\mathrm{ETc}=\mathrm{ET}_{0} \times \mathrm{Kc}
$$

em que $\mathrm{ET}_{0}$ é a evapotranspiração de referência baseado na metodologia de Penman-Monteith (ALLEN et al, 1998); e Kc - coeficiente de cultivo para a cultura do algodão, estimado pela expressão obtida por Bezerra et al. (2010), em função do número de dias após a emergência.

em que DAE são os dias após emergência.

$K c=-0,00006 \cdot D A E^{2}+0,011 \cdot D A E+0,5703$

Copos coletores foram distribuídos nas parcelas experimentais para acompanhamento da lâmina média precipitada nos tratamentos, logo após a reali- zação de cada evento de irrigação.

Foram procedidos os tratamentos fitossanitários necessários quando apareceram os primeiros sintomas de pragas e doenças, assim como o controle de plantas daninhas.

Foram avaliados os dados de produtividade de algodão em caroço (colheita da área útil da parcela), porcentagem de fibra e características inerentes à qualidade da fibra (determinadas a partir de amostra de 20 capulhos, colhidos no terço médio das plantas da área útil da parcela) como: comprimento (UHM); uniformidade (UNF); índice de fibras curtas (SFI); resistência (STR); alongamento (ELG); índice micronaire (MIC); reflectância (Rd); e grau de amarelecimento $(+b)$. As características de qualidade das fibras foram analisadas no Laboratório de Fibras e Fios da Embrapa Algodão, através do equipamento HVI (High Volume Instrument).

Os dados das variáveis avaliadas foram submetidos à análise de variância pelo teste $\mathrm{F}$ a 1 e $5 \%$ de probabilidade, sendo realizada a análise para cada ano e com os dados agrupados (análise conjunta). Quando verificado efeito significativo na análise de variância os dados obtidos nos diferentes tratamentos de natureza qualitativa (cultivares) foram comparadas através do teste de Tukey a 5\% de probabilidade e os de natureza quantitativa (lâminas de irrigação) submetidos ao estudo de regressão, a 1 e $5 \%$ de probabilidade, buscando-se ajustar equações com significados biológicos e que resultassem nos melhores níveis de significância e maiores valores de coeficiente de determinação $\left(\mathrm{R}^{2}\right)$.

\section{RESULTADOS E DISCUSSÃO}

As lâminas de irrigação aplicadas por tratamento nos dois anos de cultivo são apresentadas na Tabela 2. 
Tabela 2. Lâmina de irrigação aplicada em cada tratamento durante o ciclo de cultivo nos anos de 2012 e 2013.

\begin{tabular}{ccccc}
\hline & \multicolumn{4}{c}{ Tratamento } \\
\cline { 2 - 5 } Ano & $130 \%$ ETc & $100 \%$ ETc & $70 \%$ ETc & $40 \%$ ETc \\
\cline { 2 - 5 } $2012 *$ & 1297 & 1090 & 725 & 408 \\
$2013 *$ & 1013 & 779 & 545 & 311 \\
\hline
\end{tabular}

*Lâmina correspondente ao somatório das irrigações aplicadas desde o plantio até a colheita.

A análise de variância e teste de médias para a produtividade de algodão em caroço, porcentagem de fibras e rendimento de algodão em pluma para as cultivares BRS 286, BRS 336, BRS 335 e FiberMax 993, sob diferentes lâminas de irrigação, são apresentados na Tabela 3. Como a relação entre os quadrados médios dos dois anos foi menor que 7
(CRUZ; CARNEIRO, 2003) optou-se pela realização da análise conjunta dos dados. A interação lâminas de irrigação versus cultivares não foi significativa, assim como houve diferença significativa para as cultivares e para as lâminas de irrigação, as quais foram discutidas separadamente.

Tabela 3. Análise de variância e teste de médias para as variáveis produtividade de algodão em caroço, porcentagem de fibras e rendimento de algodão em pluma em função das cultivares e lâminas de irrigação (dados agrupados 2012/2013).

\begin{tabular}{|c|c|c|c|}
\hline \multirow[b]{2}{*}{ Anova } & \multicolumn{3}{|c|}{$\operatorname{Pr}>\mathrm{Fc}$} \\
\hline & $\begin{array}{l}\text { Produtividade de } \\
\text { algodão em } \\
\text { caroço } \\
\left(\mathrm{Kg} \mathrm{ha}^{-1}\right)\end{array}$ & $\begin{array}{c}\text { Porcentagem } \\
\text { de Fibras } \\
(\%)\end{array}$ & $\begin{array}{l}\text { Rendimento de } \\
\text { algodão em pluma } \\
\left(\mathrm{Kg} \mathrm{ha}^{-1}\right)\end{array}$ \\
\hline Irrigação (I) & $<0,01 * *$ & $<0,01 * *$ & $<0,01 * *$ \\
\hline Cultivares (C) & $<0,01 * *$ & $<0,01 * *$ & $<0,01 * *$ \\
\hline $\mathrm{I} \times \mathrm{C}$ & $0,98 \mathrm{~ns}$ & $0,65 \mathrm{~ns}$ & $0,97 \mathrm{~ns}$ \\
\hline \multicolumn{4}{|c|}{$\begin{array}{l}* * \text { Valores de } \mathrm{Pr}>\mathrm{Fc} \text { iguais ou menores que } 0,05 \text { indicam diferença } \\
\text { significativa a } 5 \% \text {, valores menores que } 0,01 \text { indicam significância a } 1 \% \text {. }\end{array}$} \\
\hline \multicolumn{4}{|c|}{ Médias } \\
\hline \multicolumn{4}{|l|}{ Irrigação } \\
\hline $40 \%$ ETc & 2225,3 & 40,7 & 1098,4 \\
\hline $70 \%$ ETc & 4254,4 & 41,5 & 1624,4 \\
\hline $100 \% \mathrm{ETc}$ & 5620,5 & 42,3 & 2150,4 \\
\hline $130 \%$ ETc & 5715,1 & 43,1 & 2676,4 \\
\hline \multicolumn{4}{|l|}{ Cultivares } \\
\hline BRS 286 & $4634,6 \mathrm{AB}$ & $43,1 \mathrm{~A}$ & $2014,7 \mathrm{AB}$ \\
\hline BRS 336 & $4070,5 \mathrm{~B}$ & $38,8 \mathrm{~B}$ & $1594,5 \mathrm{C}$ \\
\hline BRS 335 & $4183,8 \mathrm{~B}$ & $42,5 \mathrm{~A}$ & $1791,2 \mathrm{BC}$ \\
\hline FiberMax 993 & $4926,3 \mathrm{~A}$ & $43,1 \mathrm{~A}$ & $2149,2 \mathrm{~A}$ \\
\hline
\end{tabular}

Médias seguidas pela mesma letra maiúscula na coluna não diferem entre si a 5\% de probabilidade pelo teste de Tukey. 
As cultivares que apresentaram as maiores produtividades médias de algodão em caroço foram a FiberMax 993 e a BRS 286, produzindo 4.926,3 e $4.634,6 \mathrm{~kg} \mathrm{ha}^{-1}$, respectivamente. As cultivares BRS 335 e BRS 336 apresentaram produtividade média de $4.183,8$ e $4.070,5 \mathrm{~kg} \mathrm{ha}^{-1}$, nessa ordem (Tabela 3). Os resultados demonstram a ampla adaptabilidade dessas cultivares, a qual apesar de terem sido desenvolvidas para a região do cerrado brasileiro apresentaram potencial para cultivo no Semiárido em condições irrigadas. Outrossim, observa-se que mesmo as cultivares BRS 336 e BRS 335, que apresentaram as menores médias, suas produtividades médias foram superiores à média nacional na safra $12 / 13$, que foi de $3662 \mathrm{~kg} \mathrm{ha}^{-1}$ (CONAB, 2013).

Com relação a porcentagem de fibras nota-se que somente a cultivar BRS 336 diferiu das demais, com percentagem de fibras igual a $38,8 \%$. O rendimento de algodão em pluma diferiu estatisticamente entre as cultivares, sendo a FiberMax 993, BRS 286

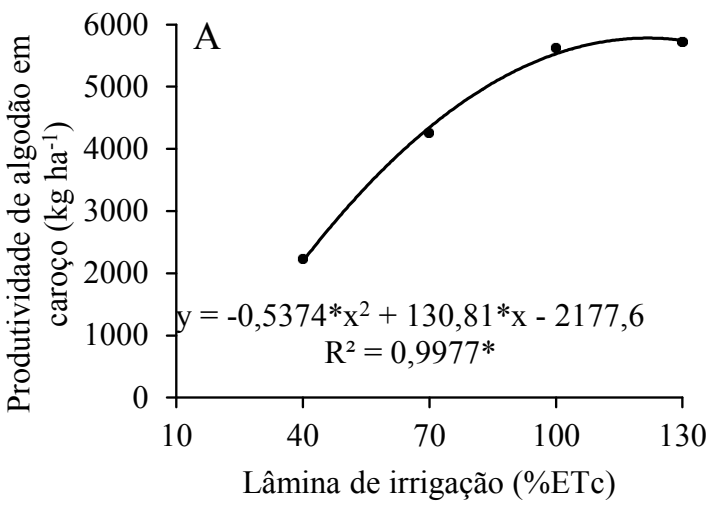

e a BRS 335 as que apresentaram os melhores resultados, quais sejam, 2.149,4 e 2.014,7 e $1.791,2 \mathrm{~kg} \mathrm{ha}^{-1}$, respectivamente (Tabela 3). O resultado do rendimento de algodão em pluma foi influenciado pela produtividade de algodão em caroço e pela percentagem de fibras das cultivares. Nota-se que a BRS 336 apresentou o menor desempenho no rendimento de algodão em pluma (1.594 $\left.\mathrm{kg} \mathrm{ha}^{-1}\right)$, como também os menores desempenhos com relação a porcentagem de fibras e produtividade de algodão em caroço. Apesar do menor desempenho deve-se ressaltar ainda que a referida cultivar apresentou rendimento de algodão em pluma superior à média nacional, que foi de $1.444 \mathrm{~kg} \mathrm{ha}^{-1}$ na safra $2012 / 2013$ (CONAB, 2013). Na Figura 1 são apresentados os gráficos que relacionam a produtividade de algodão em caroço, a porcentagem de fibras e o rendimento de algodão em pluma com as lâminas de irrigação aplicadas independentemente da cultivar utilizada.

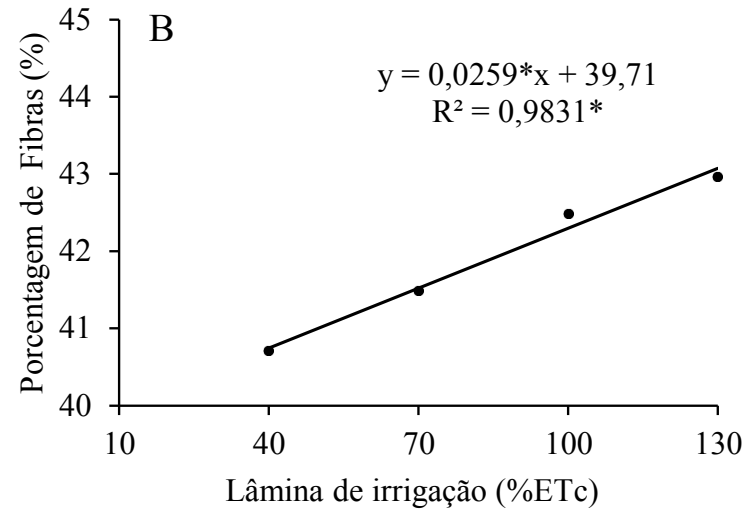

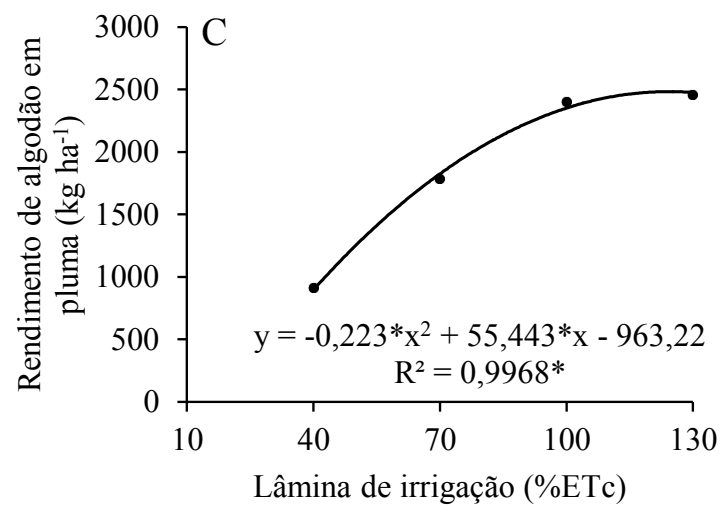

*Significativo a $5 \%$ de probabilidade.

Figura 1. Produtividade de algodão em caroço (A), porcentagem de fibras (B) e rendimento de algodão em pluma $(C) \mathrm{em}$ função das lâminas de irrigação aplicadas para quatro cultivares de algodoeiro (dados agrupados).

O déficit na irrigação do algodoeiro proporcionou declínio na produtividade de algodão em caroço, sendo este descrito por uma função polinomial com elevado coeficiente de determinação $\left(\mathrm{R}^{2}=\right.$ 0,99), decrescendo da lâmina de $130 \%$ da ETc para a lâmina de $40 \%$ da ETc (Figura 1A). A produtividade máxima de $5.732 \mathrm{~kg} \mathrm{ha}^{-1}$ foi alcançada com a lâmina de $130 \%$ da ETc. Na irrigação com déficit igual a
$70 \%$ da ETc a produtividade foi reduzida para $4.225 \mathrm{~kg} \mathrm{ha}^{-1}$, ou seja, uma redução de $26 \%$ na produtividade. Quando foi imposto um déficit maior, com lâmina de irrigação correspondente a $40 \%$ da ETc, a produtividade foi de $2.225 \mathrm{~kg} \mathrm{ha}^{-1}$, o que corresponde a uma redução de $61 \%$ em relação a máxima produtividade. Os resultados deste trabalho corroboram com os obtidos por Dagdelen et al. (2006), que ao utiliza- 
rem irrigação com lâminas variando de 867 a 257 $\mathrm{mm}$ por ciclo verificaram redução na produtividade de 5.490 para $1.780 \mathrm{~kg} \mathrm{ha}^{-1}$. DeTar (2008) também observaram redução na produtividade do algodoeiro decorrente do déficit na irrigação, sendo de $50 \%$ quando comparadas às lâminas de 50 e $100 \%$ da ETc. Onder et al. (2009), testando quatro níveis de irrigação com déficit em 2 ciclos de cultivo, demonstraram que a irrigação com déficit causa decréscimo na produtividade e nos componentes do rendimento, com queda de $40 \%$ na produção se comparadas as lâminas de irrigação de 25 e $100 \%$ da ETc, estando os resultados de acordo com os apresentados neste trabalho.

Com relação a porcentagem de fibras observa -se que esta característica também foi afetada pelas lâminas de irrigação, com maior porcentagem de fibra na medida em que se aumentou a disponibilidade de água para as plantas, tendo ajuste por modelo linear $\left(\mathrm{R}^{2}=0,983\right)$. Outros autores como Booker et al. (2006), Falkenberg et al. (2007) e Wen et al. (2013) encontraram resultados que corroboram com os apresentados no presente trabalho. Observa-se que com 70 e $40 \%$ da lâmina de irrigação a porcentagem de fibra foi de 41,5 e $40,7 \%$, respectivamente, valores menores se comparados a lâmina de $130 \%$ da ETc (43\%). Pettigrew (2004) relataram em seu estudo que o algodoeiro apresenta variação na porcentagem de fibra quando irrigado com menos que $50 \%$ da ETc. Meng et al. (2008) também apresentaram resultados que demonstram que em déficits hídricos severos $(<50 \% \mathrm{ETc})$ o algodoeiro apresenta queda na produção de fibras.

Observa-se na Figura $1 \mathrm{C}$ que o rendimento de algodão em pluma também se ajustou ao modelo polinomial, sendo resultado da influência da produtividade de algodão em caroço e da percentagem de fibra em função das lâminas de irrigação. A maior lâmina de irrigação (130\%ETc) promoveu rendimento de algodão em pluma na ordem de $2.676,4 \mathrm{~kg} \mathrm{ha}^{-1}$, enquanto que nas lâminas de 40 e $70 \%$ ETc esses valores foram de 1.098 e $1.624 \mathrm{~kg} \mathrm{ha}^{-1}$, ou seja, $58 \mathrm{e}$ $40 \%$ menores, respectivamente, se comparados a maior lâmina de irrigação $(130 \% \mathrm{ETc})$. Wen et al. (2013), testando diversas cultivares de algodão com irrigação sob déficit hídrico, encontraram decréscimos no rendimento de algodão em pluma da ordem de 28 e $33 \%$ para irrigações com 70 e $50 \%$ ETc quando comparadas a lâmina controle e afirmam que esses resultados demonstram que as lâminas de irrigação foram inadequadas para as cultivares em estudo.

$\mathrm{Na}$ Tabela 4 são apresentados os resultados da análise de variância e teste de médias para as variáveis relacionadas a qualidade tecnológica da fibra em função das lâminas de irrigação e cultivares. Para todas as variáveis avaliadas houve diferença significativa entre as cultivares. Com relação as lâminas de irrigação, não houve diferença significativa para as variáveis alongamento (ELG) e índice de micronaire (MIC) (Tabela 4). Também é observado que não ocorreu interação significativa entre os fatores e, portanto, serão apresentados de forma separada os valores médios da qualidade das fibras para as cultivares e para as lâminas de irrigação. Wen et al. (2013) também não encontraram diferenças significativas pera alongamento e micronaire, quando comparadas a irrigação total com irrigações com até 50\% de déficit.

Na Tabela 4 verifica-se que o comprimento da fibra (UHM) variou, no geral, de 27,9 a 31,5 mm (fibras médias), sendo o maior valor encontrado para a BRS 336. Para as demais características, de acordo com Santana et al. (2008), pode-se fazer as seguintes inferências: a uniformidade (UNF) foi elevada, em torno de $84 \%$, sendo o maior valor obtido pela BRS $336(85,2 \%)$ e o menor valor pela FiberMax 993 $(83,7 \%)$. O índice de fibras curtas (SFI) foi muito baixo $(<6 \%)$, a resistência (STR) para todas as cultivares foi classificada como forte (30-33 $\left.\mathrm{gf} \mathrm{tex}^{-1}\right)$. O alongamento (ELG) foi muito baixo $(<5 \%)$ para a BRS 335, baixo para FiberMax 993 e BRS 286 (5,0 a $5,8 \%$ ) e médio $(5,9$ a $6,7 \%)$ para BRS 336 . O índice micronaire variou de médio $(4,0$ a 4,9) para BRS 335 e BRS 286 a grosso $(5,0$ a 5,9) para BRS 336 e FiberMax 993, revelando que as fibras apresentaram desenvolvimento normal e completo, com fibras maduras, porém de grande perímetro. O grau de amarelo $(+b)$ e reflectância $(\mathrm{Rd})$ também foram diferenciados entre as cultivares, sendo a FiberMax 993 com maior reflectância $(82,6 \%)$ e a BRS 286 com maior grau de amarelo $(8,5)$, sendo todos classificados como branco. Essas diferenças encontradas entre as cultivares eram esperadas, pois segundo Bradow e Davidonis (2000), a maioria das características de qualidade da fibra é dependente do genótipo.

De acordo com os resultados supracitados, com exceção do índice micronaire (MIC) para as cultivares BRS 336 e FiberMax 993, considerado grosso, as demais características estão dentro do padrão desejado pela indústria têxtil, com ênfase para a resistência (STR), que ficou acima de $30 \mathrm{gf} \mathrm{tex}^{-1}$, sendo que o mínimo exigido pela indústria têxtil é 24 gf tex ${ }^{-1}$. Santana et al. (2008) afirmam que nos atuais e modernos processos de fiação as características mais importantes das fibras são a finura (micronaire) e resistência. É importante salientar que mesmo o índice micronaire (MIC), sendo classificado como grosso (BRS 336 e FiberMax 993), as mesmas se encontram dentro de uma faixa de qualidade aceitável pela indústria têxtil nacional. 
Tabela 4. Análise de variância e teste de médias para as variáveis comprimento (UHM), uniformidade (UNF), índice de fibras curtas (SFI), resistência (STR), alongamento (ELG), índice micronaire (MIC), reflectância (Rd) e grau de amarelo (+b) em função das cultivares e lâminas de irrigação (dados agrupados 2012/2013).

\begin{tabular}{ccccccccc}
\hline \multirow{2}{*}{ Anova } & \multicolumn{7}{c}{ Pr $>$ Fc } \\
\cline { 2 - 9 } & UHM & UNF & SFI & STR & ELG & MIC & Rd & + b \\
\hline & $\mathrm{mm}$ & $\%$ & $\%$ & gf tex & $\%$ & & $\%$ & -- \\
\hline Irrigação (I) & $<0,01^{* *}$ & $<0,01^{* *}$ & $<0,01^{* *}$ & $<0,01^{* *}$ & $0,06 \mathrm{~ns}$ & $0,08 \mathrm{~ns}$ & $<0,01^{* *}$ & $<0,01^{* *}$ \\
Cultivares (C) & $<0,01^{* *}$ & $<0,01^{* *}$ & $<0,01^{* *}$ & $<0,01^{* *}$ & $<0,01^{* *}$ & $<0,01^{* *}$ & $<0,01^{* *}$ & $<0,01^{* *}$ \\
I x C & $0,89 \mathrm{~ns}$ & $0,21 \mathrm{~ns}$ & $0,77 \mathrm{~ns}$ & $0,97 \mathrm{~ns}$ & $0,36 \mathrm{~ns}$ & $0,59 \mathrm{~ns}$ & $0,44 \mathrm{~ns}$ & $0,81 \mathrm{~ns}$
\end{tabular}

*Valores de $\mathrm{Pr}>\mathrm{Fc}$ iguais ou menores que 0,05 indicam diferença significativa a 5\%, valores menores que 0,01 indicam ignificância a $1 \%$.

\begin{tabular}{ccccccccc}
\hline & \multicolumn{7}{c}{ Médias } \\
\hline Irrigação & & & & & & \\
$40 \%$ ETc & 27,3 & 83,4 & 7,85 & 30,3 & 5,43 & 4,88 & 80,9 & 7,86 \\
$70 \%$ ETc & 29,5 & 84,1 & 7,10 & 31,8 & 5,07 & 4,88 & 81,4 & 7,82 \\
$100 \%$ ETc & 29,9 & 85,5 & 6,52 & 33,1 & 5,41 & 5,05 & 81,9 & 8,37 \\
$130 \%$ ETc & 30,1 & 84,9 & 6,65 & 32,5 & 5,37 & 4,92 & 82,4 & 8,18 \\
Cultivares & & & & & & & & \\
BRS 286 & $27,9 \mathrm{C}$ & $84,3 \mathrm{BC}$ & $7,2 \mathrm{AB}$ & $30,6 \mathrm{~B}$ & $5,7 \mathrm{~B}$ & $4,9 \mathrm{~A}$ & $81,3 \mathrm{~B}$ & $8,5 \mathrm{~A}$ \\
BRS 336 & $31,5 \mathrm{~A}$ & $85,2 \mathrm{~A}$ & $6,4 \mathrm{C}$ & $35,3 \mathrm{~A}$ & $4,4 \mathrm{D}$ & $5,1 \mathrm{~A}$ & $81,2 \mathrm{~B}$ & $7,6 \mathrm{C}$ \\
BRS 335 & $29,1 \mathrm{~B}$ & $84,7 \mathrm{C}$ & $7,0 \mathrm{~B}$ & $30,3 \mathrm{~B}$ & $6,1 \mathrm{~A}$ & $4,6 \mathrm{~B}$ & $81,5 \mathrm{~B}$ & $8,2 \mathrm{AB}$ \\
FiberMax 993 & $28,4 \mathrm{C}$ & $83,7 \mathrm{C}$ & $7,4 \mathrm{~A}$ & $31,4 \mathrm{~B}$ & $5,0 \mathrm{C}$ & $5,1 \mathrm{~A}$ & $82,6 \mathrm{~A}$ & $7,9 \mathrm{BC}$ \\
\hline
\end{tabular}

** Significativo a $1 \%$ de probabilidade. Médias seguidas pela mesma letra maiúscula na coluna não diferem entre si a $5 \%$ de probabilidade pelo teste de Tukey.

Na Figura 2 são apresentados os gráficos que relacionam as variáveis da qualidade da fibra com as lâminas de irrigação aplicadas.

$\mathrm{O}$ índice de fibras curtas (SFI) diminui com o aumento das lâminas de irrigação (Figura 2A). De acordo com Bradow e Davidonis (2000), apesar do comprimento da fibra ser um traço primariamente genético o índice de fibras curtas é dependente, além do genótipo, das condições de cultivo, dentre elas a disponibilidade hídrica.

Com relação a resistência das fibras (STR) (Figura 2B), observa-se que a mesma apresentou aumento, de acordo com a função ajustada, até a lâmina de $104 \% \mathrm{ETc}$, com valor máximo de 32,69 gf tex ${ }^{-1}$. A partir desse ponto houve decréscimo na resistência das fibras com o aumento na lâmina de irrigação. Dagdelen et al. (2009) também encontraram maior resistência das fibras com a lâmina de $100 \%$ da ETc quando comparada com as demais lâminas e citam que a resistência das fibras decresce com o aumento do déficit hídrico. Esse mesmo comportamento foi apresentado por Johnson et al. (2002) ao encontrarem correlação positiva entre a resistência da fibra e a disponibilidade de água no solo. Com relação ao excesso de água, alguns estudos demonstram que a resistência das fibras decresce com o aumento da precipitação/irrigação, o que pode ser comprovado com o decréscimo nos valores para irrigações superiores a $104 \%$ da ETc (Figura 2B). Com base em resultados de três anos de estudos, Bradow e Davidonis (2000) concluíram que a resistência das fibras apresenta correlação negativa com a produtividade, corroborando com os resultados deste ensaio, visto que na lâmina de $130 \%$ ETc foram obtidas as maiores produtividades (Figura 1A). Dessa forma, pode-se inferir que tanto o déficit quanto o excesso de água pode influenciar negativamente a resistência das fibras. 

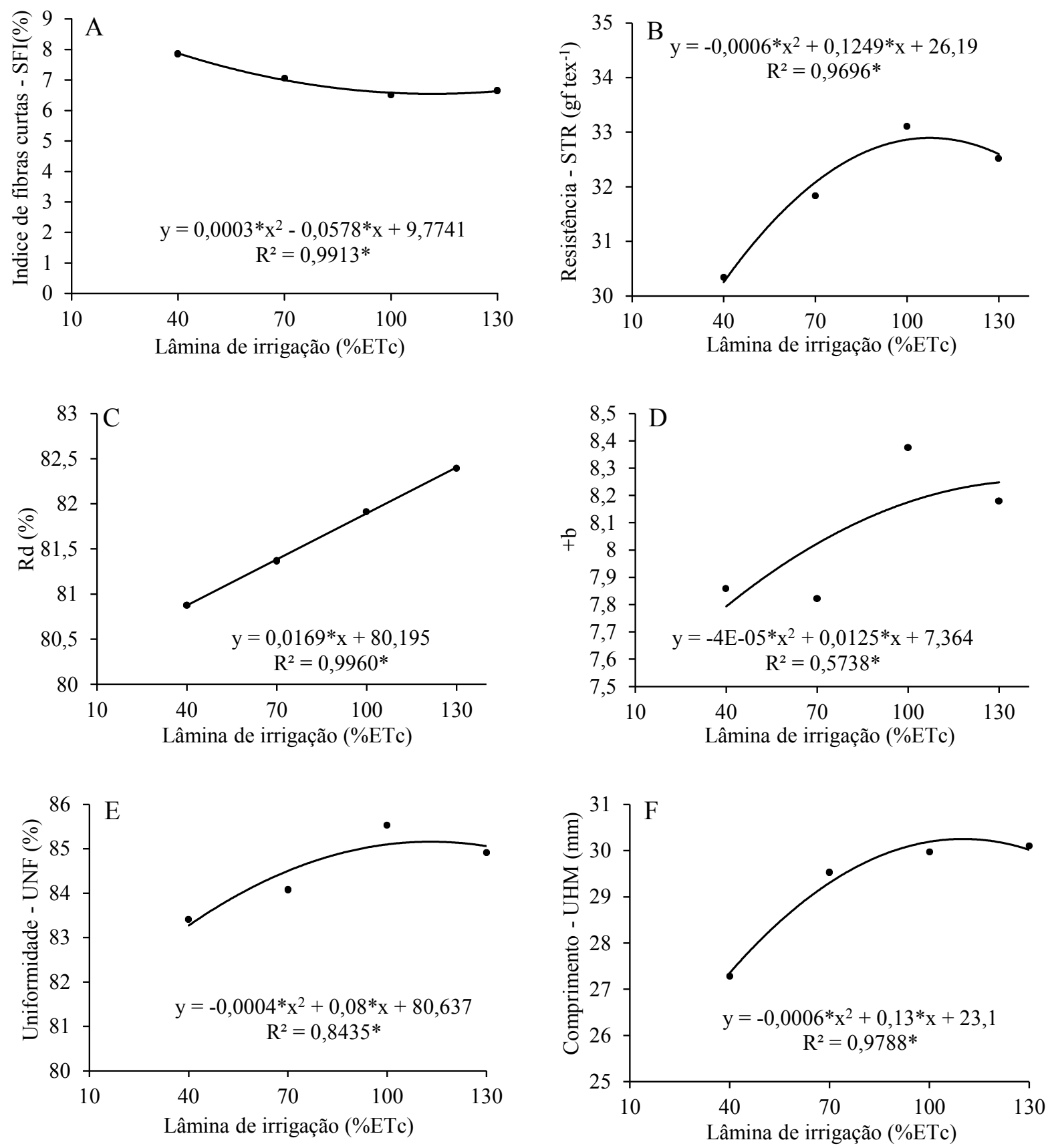

*Significativo a $5 \%$ de probabilidade.

Figura 2. Índice de fibras curtas (A), resistência (B), reflectância - Rd (C), grau de amarelo - +b (D), uniformidade (E) e comprimento $(\mathrm{F})$ das fibras do algodoeiro em função das lâminas de irrigação aplicadas para quatro cultivares de algodoeiro (dados agrupados).

Com relação às características reflectância $(\mathrm{Rd} \%)$ e grau de amarelo $(+\mathrm{b})$, as quais estão relacionadas a cor da fibra, ambas tiveram o mesmo comportamento, aumentando com o incremento da lâmina de irrigação (Figura 2C e D), sendo que o grau de amarelo $(+b)$ não apresentou resultados conclusivos, variando muito em função das lâminas de irrigação. Segundo Bradow e Davidonis (2000), a cor da fibra está diretamente ligada a fatores ambientais durante a estação de cultivo, que neste trabalho foi o estresse hídrico. Outros fatores podem ter influenciado esses valores, como a aplicação de desfolhantes e desse- cantes, ataque de pragas, entre outros.

A uniformidade da fibra foi afetada pelas lâminas de irrigação, tendo correlação positiva entre as variáveis (Figura 2E), corroborando com os resultados apresentados por Wen et al. (2013). Ainda segundo o autor ora citado, condições ambientais subótimas, como o estresse hídrico, pode diminuir a taxa de alongamento ou encurtar o período de alongamento das fibras, diminuindo seu comprimento e uniformidade.

O comprimento médio da fibra variou de 27,2 a $30 \mathrm{~mm}$ (Figura 2F), havendo incremento com o 
aumento da lâmina de irrigação, sendo as maiores diferenças encontradas entre a maior lâmina (130\% ETc) e a menor lâmina $(40 \% \mathrm{ETc})$, indicando que com o déficit hídrico acentuado tem-se fibra de qualidade inferior, se comparado aos demais tratamentos. Esse comportamento também foi observado por outros autores, como Wen et al. (2013) e Dagdelen et al. (2009), que afirmam que muitas características de qualidade das fibras são influenciadas diretamente por variáveis ambientais, como o estresse hídrico. Autores como Sui et al. (2014) e Balkcom et al. (2006) afirmam que o aumento da irrigação implica em aumento no comprimento da fibra.

Segundo Dagdelen et al. (2009), o efeito do estresse hídrico no comprimento da fibra depende da duração do estresse e do momento no ciclo em que ele ocorre. A ocorrência de estresse hídrico logo após o florescimento e durante a fase de alongamento da fibra pode reduzir seu comprimento devido a ligação direta com os mecanismos mecânicos e fisiológicos de expansão celular (PETTIGREW, 2004; RITCHIE et al., 2004). Essas afirmações explicam os resultados aqui encontrados, visto que no tratamento de $40 \%$ ETc as plantas sofreram estresse hídrico durante todo o ciclo de cultivo.

\section{CONCLUSÕES}

A lâmina de irrigação adequada para as cultivares de algodoeiro herbáceo expressarem o máximo potencial de produtividade e qualidade de fibra, principalmente com relação ao seu comprimento, deve ser maior ou igual a $103 \% \mathrm{ETc}$.

As cultivares FiberMax 993 e BRS 286 apresentaram as maiores produtividades.

As cultivares FiberMax 993, BRS 286 e BRS 335 apresentaram as maiores porcentagens de fibras.

No que diz respeito à qualidade da fibra esta decresceu com a redução na lâmina de irrigação.

No geral, a fibra produzida é de boa qualidade, mesmo em condições de déficit hídrico, estando dentro da faixa de qualidade aceitável pela indústria têxtil nacional.

Em regiões com déficit hídrico o algodoeiro pode ser irrigado com lâmina de $70 \%$ da ETc, com produtividade média acima de $4.000 \mathrm{~kg} \mathrm{ha}^{-1} \mathrm{e}$ boa qualidade da fibra.

\section{REFERÊNCIAS}

ANA. Agência Nacional das Águas. Conjuntura dos Recursos Hídricos no Brasil 2013. Disponível em: <http://arquivos.ana.gov.br/institucional/spr/ conjuntura/

ANA_Conjuntura_Recursos_Hidricos_Brasil/

ANA_Conjuntura_Recursos_Hidricos_Brasil_nov.pd f>. Acesso em: 28 mar. 2014.
BALKCOM, K. S. et al. Cotton yield and fiber quality from irrigated tillage systems in the Tennessee Valley. Agronomy Journal, Madson, v. 98, n. 3, p. 596-602, 2006.

BASAL, H. et al. Effects of Deficit Drip Irrigation Ratios on Cotton (Gossypium hirsutum L.) Yield and Fiber Quality. Journal of Agronomy and Crop Science, Berlin, v. 195, n. 1, p. 19-29, 2009.

BOOKER, J. D. et al. Variable rate irrigation on cotton lint yield and fiber quality. In: BELTWIDE COTTON CONFERENCES, 2006, San Antonio. Anais... San Antonio: The Cotton Foundation, 2006. p. $1768-1776$

BRADOW, J. M.; DAVIDONIS, G. H. Quantitation of fiber quality and the cotton production-processing interface: a physiologist's perspective. The Journal of Cotton Science, Baton Rouge, v. 4, n. 1, p. 34-64, 2000

BRITO, G. G. et al. Physiological traits for drought phenotyping in cotton. Acta Scientiarum Agronomy, Maringá, v. 33, n. 1, p. 117-125, 2011.

CONAB. Companhia Nacional de Abastecimento. Acompanhamento da Safra Brasileira: Grãos. Décimo Segundo Levantamento, Setembro - 2013. Disponível em: <http://www.conab.gov.br>. Acesso em: 13 mar. 2014

CRUZ, C. D.; CARNEIRO, P. C. S. Modelos biométricos aplicados ao melhoramento genético. 2 ed. Viçosa, MG: UFV, 2003. 585 p.

DAGDELEN, N. et al. Water-yield relation and water use efficiency of cotton (Gossypium hirsutum L.) and second crop corn (Zea mays L.) in western Turkey. Agricultural Water Management, Amsterdam, v. 82, n. 1, p. 63-85, 2006.

DAGDELEN, N. et al. Different drip irrigation regimes affect cotton yield, water use efficiency and fiber quality in western Turkey. Agricultural Water Management, Amsterdam, v. 96, n. 1, p. 111-120, 2009.

DE TAR, W. R. Yield and growth characteristics for cotton under various irrigation regimes on sandy soil. Agricultural water management, Amsterdam, v. 95, n. 1, p. 69-76, 2008.

SUI, R. et al. Effect of supplemental irrigation and graded levels of nitrogen on cotton yield and quality. Journal of Agricultural Science, Toronto, v. 6, n. 2, p. 119-131, 2014.

FALKENBERG, N. R. et al. Remote sensing of biotic and abiotic stress for irrigation management of 
cotton. Agricultural Water Management, Amsterdam, v. 87, n. 1, p. 23-31, 2007.

JOHNSON, R. M. et al. Variability in cotton fiber yield, fiber quality, and soil properties in a southeastern coastal plain. Agronomy Journal, Madson, v. 94, n. 6, p. 1305-1316, 2002.

MENG, Z. et al. Effect of regulated deficit irrigation on growth and development characteristics in cotton and its yield and fiber quality. Cotton Science, Henan, v. 20, n. 1, p. 39-44, 2008.

ONDER, D. et al. Effect of different irrigation water level on cotton yield and yield components. African Journal of Biotechnology, Lagos, v. 8, n. 8, p. 1536 $-1544,2009$.

PETTIGREW, W. T. Moisture deficit effects on cotton lint yield, yield components, and boll distribution. Agronomy Journal, Madson, v. 96, n. 2, p. 377 $-383,2004$.

RITCHIE, G. L. et al. Cotton growth and development. Georgia: CAES-UGA, 2004. 16 p. (Boletim 1252)

SANTANA, J. C. F. et al. Características da fibra e do fio do algodão. In: BELTRÃO, N. E. M.; AZEVEDO, D. M. P. (Ed.). O agronegócio do algodão no Brasil. Brasília: Embrapa Informação Tecnológica, 2008. v.2, cap. 31, p. 1099-1120.

SNOWDEN, C.; RITCHIE, G.; THOMPSON, T. Water use efficiency and irrigation response of cotton cultivars on subsurface drip in west Texas. The Journal of Cotton Science, Baton Rouge, v. 17, n. 1, p. 1-9, 2013.

WEN, Y. et al. Lint yield, lint quality, and economic returns of cotton production under traditional and regulated deficit irrigation schemes in southwest Texas. The Journal of Cotton Science, Baton Rouge, v. 17, n. 1, p. 10-22, 2013. 